\title{
Role of Landscape Elements in Ameliorating Adverse Pedestrian Level Winds in the Vicinity of Tall Buildings
}

\author{
K. Mohan, R.G.J. Flay, A. Gairola, N. Kwatra and M. Mukherjee
}

\begin{abstract}
Tall buildings cater to the need for increased workspace with a reduced footprint, enhance the skyline, and image and increase the prestige of a city. Tall buildings also tend to intercept upper level high velocity winds and deflect them down to ground level, giving rise to conditions that could be unpleasant or even dangerous to pedestrians. Such accelerated winds also reduce the appeal of plazas, outdoor cafes, parks and pedestrian access-ways. Vertically accelerated downward wind flows can be mitigated with the help of architectural elements like podia or, canopies. Horizontally accelerated flows are best ameliorated with soft and hard landscape elements such as trees, shrubs and porous fences. This paper reports results of wind tunnel investigations that have been carried with the objective of assessing the role of landscape elements in moderating the pedestrian level wind environment in the vicinity of tall buildings. The tests have been carried out in the de Bray boundary layer wind tunnel at the University of Auckland on a representative model of a tall building suburb in New Delhi using the erosion technique enhanced with an image processing system. The results of the tests have brought out the effectiveness of landscape elements such as trees and porous fences in mitigating adverse horizontal winds in the vicinity of tall buildings.
\end{abstract}

Keywords--- Erosion Patterns, Landscape Elements Pedestrian Level Winds, Tall Buildings

\section{INTRODUCTION}

$\mathrm{T}$ HE wind environment in the vicinity of tall buildings is a matter of concern for urban designers and architects as tall buildings deflect higher upper level winds to ground level creating unpleasant and at times dangerous conditions for pedestrians. Penwarden [1] reports cases of two elderly women in the U.K. who died as a result of injuries sustained

K. Mohan, Senior Professor, Gitam School of Architecture, Gitam University, Visakhapatnam, India. E-mail: profkmohan@gmail.com

R.G.J. Flay, Professor and Deputy Head, Department of Mechanical Engineering, University of Auckland, New Zealand.

A. Gairola, Associate Professor and Head, Centre of Excellence in Disaster Mitigation and Management, IIT Roorkee, Roorkee, India.

N. Kwatra, Associate Professor, Department of Civil Engineering, Thapar University, Patiala, India.

M. Mukherjee, Assistant Professor, Dept. of Architecture and Planning, IIT-Roorkee, Roorkee, India.

DOI: 10.9756/BIJIEMS.1720 from skull and head injuries after being blown off their feet by high winds at the base of tall apartment buildings.

Landscaping is an inexpensive and attractive option for mitigating adverse ground level winds in the vicinity of tall buildings. Trees possess a small foot print but provide a large canopy that can obstruct, deflect or filter winds, without obstructing traffic and pedestrian movement.

Urban trees prevent solar radiation from heating the surrounding buildings and surfaces, cool the air by transpiration and reduce wind speed Akbari et al., [5]. Strategic placement of trees and landscape elements such as porous fences, apart from mitigating adverse winds, can also help in augmenting wind speeds in stagnant zones. However, there is little available knowledge of the absolute or relative effects of trees and buildings on wind at or below building height in residential neighborhoods [3]. A CFD (Computational Fluid Dynamics) study by Klem [6] on the effect of windbreaks on the wind flow patterns in a low rise cluster of seven buildings in Warsaw has shown that trees can significantly reduce ground level winds. However there is a dearth of wind tunnel investigations on the effect of landscape elements in moderating the impact of strong pedestrian level winds around tall buildings. The aim of this research is to carry out an assessment of the impact of soft and hard landscape elements in ameliorating adverse pedestrian level winds in the vicinity of tall buildings through wind tunnel investigations.

\section{EXPERIMENTAL APPROACH}

A typical wind tunnel study into the effects of a building development on pedestrian level wind conditions requires the combination of statistical meteorological data, aerodynamic information and comfort criteria [2].

Meteorological information comprises long term wind statistics, usually for at least ten to fifteen years, which is usually collected from a meteorological station in open terrain. In the present study wind climate for the study site has been established from long term wind records for a period of thirteen years from 1989-2003 for New Delhi ( Palam), obtained from the Indian Meteorological Department, Pune. This information is in the form of wind roses for each month for the morning hours (8a.m) and evening hours (5p.mThe wind roses give the direction and speed of winds from different directions for each month ranging from $0.3 \mathrm{~m} / \mathrm{s}$ to greater than $5.3 \mathrm{~m} / \mathrm{s}$ for 16 directions. The wind data for all the months has been summed up to obtain the cumulative 
frequency distribution of winds with different speeds for different directions. winds ranging from $0.3 \mathrm{~m} / \mathrm{s}$ to more than $5.3 \mathrm{~m} / \mathrm{s}$ for 16 wind directions annually.

The wind climate data for Delhi (Palam) thus obtained has been analyzed by fitting Weibull distribution for each wind direction, ( which gives the annual probability of exceedence of different wind speeds) by obtaining appropriate values of the coefficients $k, A$ and $c$ for all the predominant directions for which the wind tunnel tests have been carried out. The Weibull coefficients $\mathrm{k}, \mathrm{A}$ and $\mathrm{C}$ for Delhi have been incorporated in the software program in the image processing system in the de Bray wind tunnel at Auckland. This is to ensure that the output from the image processing system in the form of probability exceedence maps obtained by combining the wind climate data and wind tunnel test would be relevant for locations in New Delhi.

The second step involves linking this regional wind climate data with the information obtained from the wind tunnel tests. This linkage is necessary to bring down the regional wind data to the site in question. This is done by inserting the wind information obtained from the wind tunnel tests which is in the form of wind speed ratios into the Weibull distribution to yield probability of exceedence maps for each wind direction tested for. In other words the combination of the long term wind climate data and the wind speed ratios obtained from the wind tunnel tests gives the percentage of time various wind speeds are exceeded for the point of interest.

The wind tunnel tests have been carried out for eight predominant wind directions for Auckland, namely $30^{\circ}, 60^{\circ}$, $90^{\circ}, 210^{\circ}, 240^{\circ}, 2700$ and $300^{\circ}$. In order to make these wind directions synchronize with the predominant wind direction for Delhi, the orientation of the model in the wind tunnel has been made to coincide with the predominant wind directions for Delhi. The reason for carrying out these adjustments is to ensure that although the wind tunnel tests have been carried out in a wind tunnel at Auckland (as the facilities of carrying out wind tunnel tests using the erosion technique is not available in the wind tunnels at India) the wind information and the wind tunnel results yield probability of exceedence maps for New Delhi. A description of these adjustments and the method of linking the wind climate of New Delhi with the wind speed ratios obtained from the wind tunnel tests is explained in detail elsewhere [7].

Thereafter the results have been interrogated against published comfort criteria to judge the local wind climate. The assignment of pedestrian criteria requires the proportion of time that certain wind speeds are exceeded for all directions and this value is calculated by summing up the proportion of time that wind speeds exceed a certain speed for each point for all directions. In the present study the results of the wind tunnel study have been compared with the comfort criteria for Auckland City (since pedestrian wind comfort and safety criteria is yet to be formulated for the Indian context and the Auckland comfort criteria is in line with most universally accepted criteria) which specifies the limiting wind speeds under different categories for different pedestrian activities [10].This process has resulted in the identification of excessively windy zones, and in ensuring whether the wind speeds in different parts of the layout are acceptable for the intended activity occurring in these places.

\subsection{The Erosion Technique}

Wind tunnel techniques commonly used for investigating pedestrian level winds are normally classified as Point Methods and Area Methods. Point methods which include techniques such as hot-wire or hot film anemometry, Irwin probes and thermistors measure wind conditions at discrete points around the model. The Scour or Erosion Technique is an area method for determining the windiness of a project site [3] and [11]. The erosion technique using bran as the erodible material and enhanced with an image processing system developed by Eaddy [8] and [9] at the University of Auckland has been adopted for carrying out the wind tunnel investigations in the present study.

For the erosion tests a scaled model is placed in the wind tunnel and a non-cohesive granular material like sand or bran is spread uniformly over the area of interest. The wind speeds are gradually increased in increments starting from zero to $5.75 \mathrm{~m} / \mathrm{s}$. The areas where the granular material is scoured away first are the windiest areas, while areas that are scoured later as the wind speed increases represent progressively less windy areas. $U$ ref denotes the wind speed measured at reference height, when first signs of erosion are recorded. The ratio between the threshold speed of bran and the wind speed measured at the reference height $U$ ref in the tunnel when erosion occurs gives the discomfort parameter denoted by $\Psi$. The threshold speed of the erodible material for erosion to occur is known through earlier calibration. The average wind speed causing the bran particle to move is about $2.5 \mathrm{~m} / \mathrm{s}$.

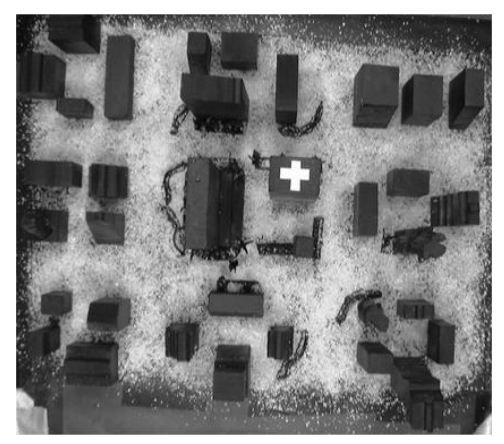

Figure 1: Bitmap Image of Layout with the Addition of Bran and with Landscape Elements in Place for $\mathrm{u}_{\mathrm{ref}}=0 \mathrm{~m} / \mathrm{s}$ and

$$
\Theta=0^{0}
$$

Photographs of the model without the addition of bran without the wind tunnel speed turned on, i.e., $0 \mathrm{~m} / \mathrm{s}$ wind speed and the erosion patterns formed by 10 subsequent speeds ranging from $1.40 \mathrm{~m} / \mathrm{s}$ to $5.75 \mathrm{~m} / \mathrm{s}$ namely $1.40 \mathrm{~m} / / \mathrm{s}, 1.75 \mathrm{~m} / \mathrm{s}, 2.45 \mathrm{~m} / \mathrm{s}, 2.85 \mathrm{~m} / \mathrm{s}, 3.35 \mathrm{~m} / \mathrm{s}, 3.90 \mathrm{~m} / \mathrm{s}, 4.35 \mathrm{~m} / \mathrm{s}, 4$. $80 \mathrm{~m} / \mathrm{s}, 5.30 \mathrm{~m} / \mathrm{s}$ and $5.75 \mathrm{~m}$ are obtained by the image processing system for 8 predominant wind directions namely $0^{\circ}, 30^{\circ}, 60^{\circ}, 90^{\circ}, 210^{\circ}, 240^{\circ}, 270^{\circ}$, and $300^{\circ}$. The threshold speed for bran, i.e. the speed at which the bran particle gets eroded is $2.4 \mathrm{~m} / \mathrm{s}$ as mentioned earlier. If the bran particle gets eroded at a lower speed, say $1.4 \mathrm{~m} / \mathrm{s}$ it would indicate that the 
extra speed for the bran particle to get eroded is supplied due to accelerated wind speeds induced by the buildings in the model. If erosion occurs in areas on the model when subjected to higher wind tunnel speeds such as $5.3 \mathrm{~m} / \mathrm{s}$ or 5.75 it would indicate that these are areas of wind stagnation. A bitmap image of the Layout with the addition of bran and with landscape elements in place for $U_{\text {ref }}=0 \mathrm{~m} / \mathrm{s}$ is shown in Figure 1.

Figure 2 shows another bitmap image for the same layout after erosion has taken place for $U_{\text {ref }}=4.35 \mathrm{~m} / \mathrm{s}$ and $\theta=0^{0}$

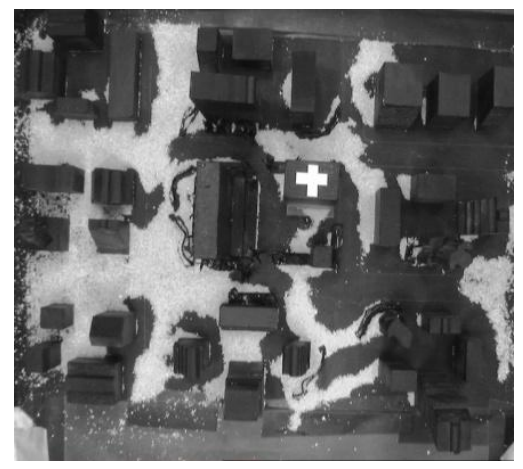

Figure 2: Bitmap Image Showing Erosion Patterns for $\mathrm{U}_{\text {ref }}=4.35 \mathrm{~m} / \mathrm{s}$ and $\theta=0^{0}$

\subsection{The Image Processing System}

The main advantage of the image processing system is that it removes the observer from the wind tunnel testing process. Further it improves the accuracy and repeatability of the tests and also reduces the time taken for conducting each test. Earlier testing procedure using the erosion technique at the University of Auckland required an operator to observe the movement of the bran particles as the speed of the wind tunnel was increased in predetermined steps, and to record the speeds which cause the bran particles to move. The disadvantage with this testing procedure is that it is somewhat subjective, depending on what the observer records and requires some practice to achieve consistency.

The system is based around a desktop IBM compatible computer and the data is acquired by a Data Translation PCI Mach Series monochrome frame grabber connected to a Panasonic charge coupled device (CCD) camera which is mounted in the roof of the wind tunnel is shown in Figure 3 and The flow diagram of the image processing system developed at the University of Auckland by Eaddy [9] is given in Figure 4.

The image processing system typically consists of four essential components:

1. An image acquisition system: A flatbed scanner or a video recorder or as in the present case a charge coupled camera form part of the image acquisition system.

2. A device known as a frame grabber to convert the electrical or analog video signal of the image acquisition system into a digital image which could be stored.
3. A personal computer or a work station that provides the processing power.

4. Image processing software that provides the tools to manipulate and analyze the images.

The acquisition component converts a visual signal into an electronic signal and thereafter a digitizing unit (frame grabber) converts these signals into digital form which can then be stored and processed by a computer.

The storage component is divided into three categories, viz, short term storage for use during processing, on-line storage during processing, on line storage for quick recall and archival storage.

Processing comprises of a set of algorithms chosen by the user for enhancing objects of interest in the image. The first stage of processing comprises of generation of erosion maps for each wind direction tested. The processing operations comprise of a number of sub processes (which are mainly morphological image processing operations) such as image enhancement, erosion pattern extraction, pattern drawing and image correlation.
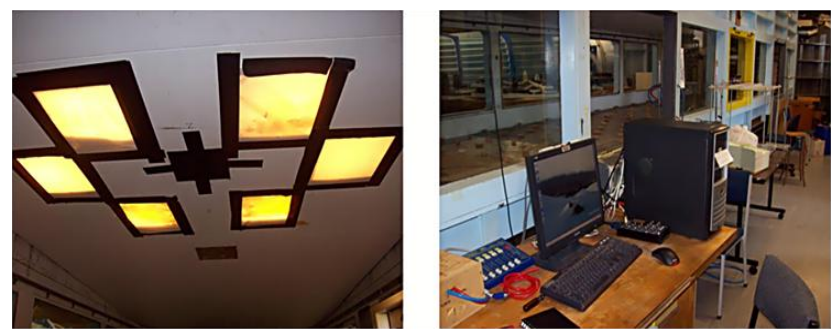

Figure3: Photograph Showing Light Settings and the CCD Camera Mounted in the Roof of the Wind Tunnel

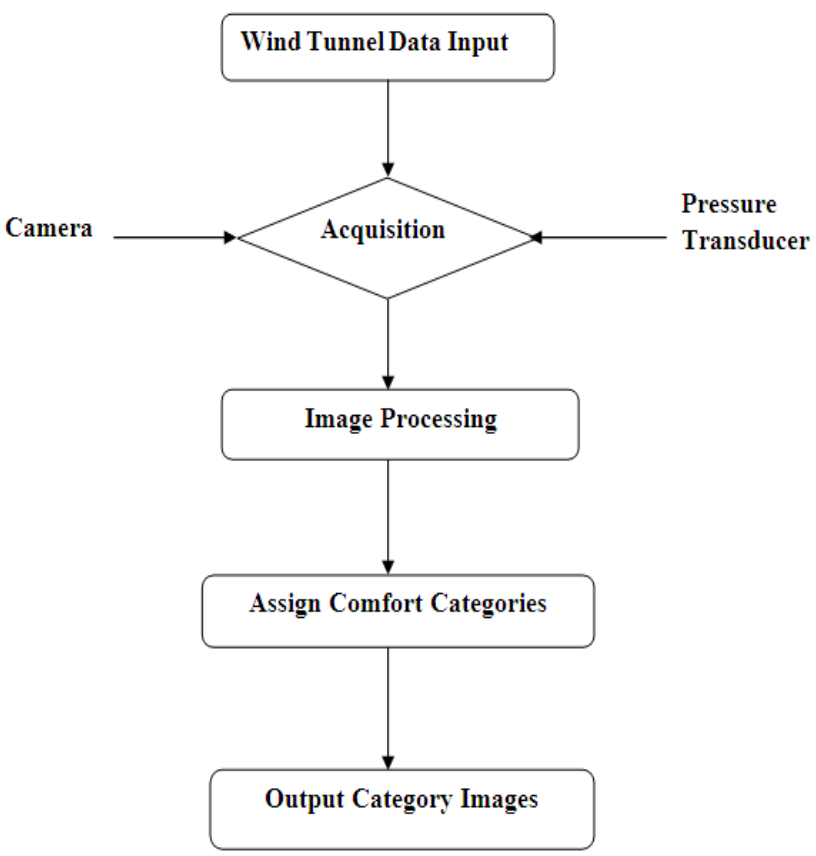

Figure 4: Flow Diagram of the Image Processing System Image Source: eaddy [9] 


\section{EXPERIMENTAL SET-UP}

Pedestrian wind investigations have been conducted in the low speed section of the de Bray wind tunnel located in the Aerodynamics Lab of the Mechanical Engineering Department at the University of Auckland. It is a closed circuit wind tunnel consisting of high speed and low speed sections. Wind engineering studies are usually conducted in the low speed section. This section has a length of approximately $9 \mathrm{~m}$ and a width of $1.83 \mathrm{~m}$. The roof height is adjustable and it is always contoured to give zero pressure gradients over the wind tunnel model. Wind speeds of up to $15 \mathrm{~m} / \mathrm{s}$ are possible in the low speed section. There is a removable flow conditioning section at the beginning of the test section for trip barriers etc. An upstream view of the wind tunnel is shown in Figure 5.

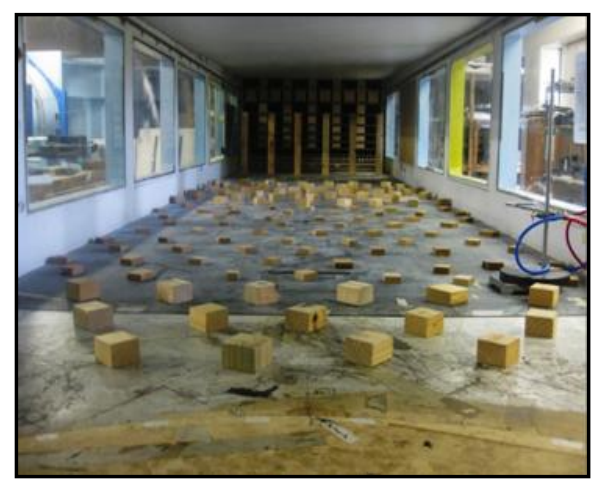

Figure 5: Upstream View of the de-bray Wind Tunnel

The velocity and turbulent intensity profiles necessary to validate the boundary layer set up have been measured with a Cobra probe attached to the traversing rig installed in the de Bray wind tunnel. The turbulent intensity and velocity profiles as plotted along with the ideal profiles from AS/NZS1170:20022 for terrain category 3 conditions are shown in Figure 6(a) and 6(b) respectively. The profiles have been recorded at the centre of the turntable, edge of the turntable and adjacent to the edge metal i.e. the walls of the wind tunnel.

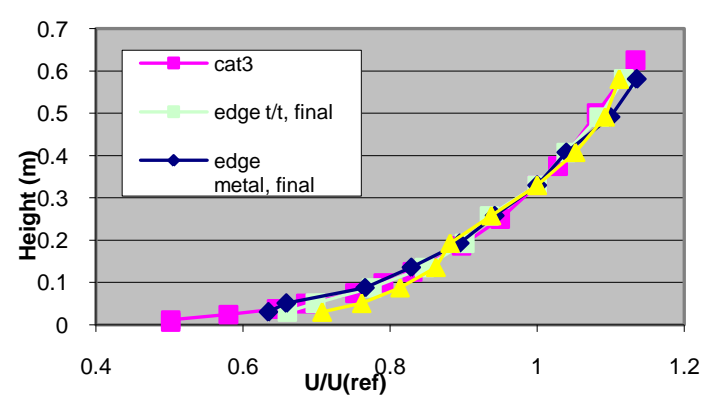

Figure 6(a): Graph of Velocity Profile

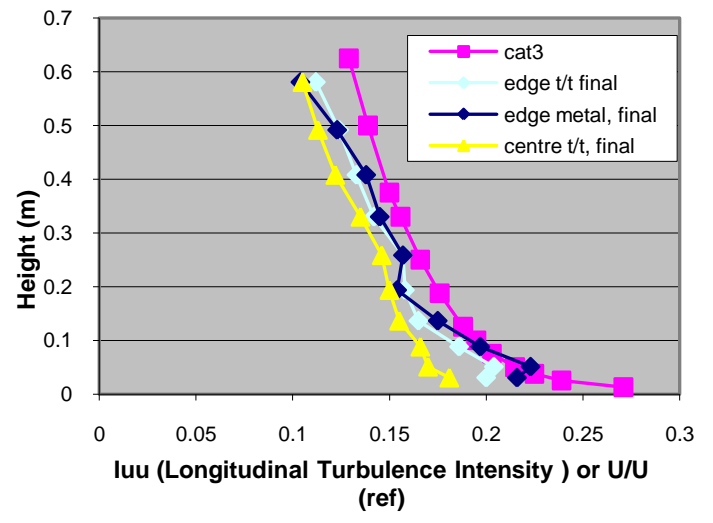

Figure 6(b): Graph of Turbulence Intensity Profile

\section{EXPERIMENTAL PROCEDURE}

The sequence of operations followed in the present investigations and which are typically followed for all erosion tests in the de Bray wind tunnel are given below:

1. The model is assembled with the area of interest located at the centre of the turntable which can be rotated to simulate wind flow from different directions. The turntable is set to $0^{\circ}$, and the model arranged so that it is lined up with the $0^{\circ}$ angle correctly.

2. The model is fixed to the turntable with black masking tape and areas adjacent to the model coming within the range of the camera are covered with black sheet.

3. The model is arranged so that the area of interest is directly under the camera and a white cross is fixed on one of the buildings within the area of interest. This acts as a means of orientation for the camera for correct orientation with subsequent rotations.

4. Next the image grabber software is loaded and after following the onscreen instructions an image preview is started when it becomes available.

5. Using the image preview the light settings are adjusted and saved for each direction. This ensures that the model is as brightly lit as possible, without creating any shadows or glare on walkways that could mask bran (the erodible material) underneath.

6. The lighting levels are adjusted to the previously recorded values.

7. The no material image is taken for the $0^{\circ}$ direction.

8. Next bran is carefully sprinkled over the area to be tested. The bran layer should be as thin as possible so as to not leave any black gaps showing through.

9. A brush is used to stipple the bran to spread it more uniformly. The model buildings are dusted free of any bran that might have fallen on them while sprinkling.

10. The wind tunnel is switched on and the zero velocity images are recorded by the charge coupled camera fixed to ceiling above the turntable.

11. The wind speed is increased in increments and wind speed is held constant for 90 seconds during which period the erosion patterns are completely formed. 
These patterns are photographed by the CCD camera and stored by the image processing system.

12. The above process is continued until all the wind speeds are complete.

13. When the last wind speed test is completed the wind speed is brought to zero before stopping the tunnel. This is important to prevent the wind tunnel starting at a higher speed when the next cycle begins.

14. After the completion of one cycle of testing the eroded bran is removed from the model.

In areas identified to be excessively windy, mitigation measures in the form of landscape elements such as trees and porous fences have been added and the wind tunnel process is repeated once again as done without the mitigation measures. A comparison of the bitmap images without and with the landscaping elements clearly shows the effectiveness of the mitigation measures.

The layout plan of tall buildings used for the present investigations is shown in Figure 7. A bird's eye view of the layout without and with landscaping is shown in Figures 8 and 9 respectively. Figure 10 shows a bitmap image giving the location of the landscape elements with the addition of bran, the erodible material sprinkled on the floor of the model. Erosion patterns with landscaping for $\mathrm{U}_{\text {ref }}=5.75 \mathrm{~m} / \mathrm{s}$ for $\theta=0^{0}$ are shown in Figures 11 and 12 respectively.

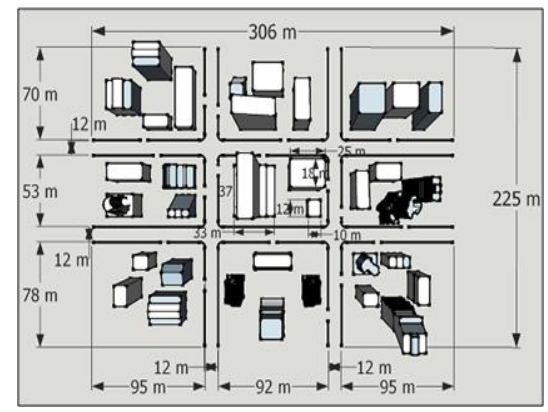

Figure 7: Layout of the Cluster of Tall Buildings

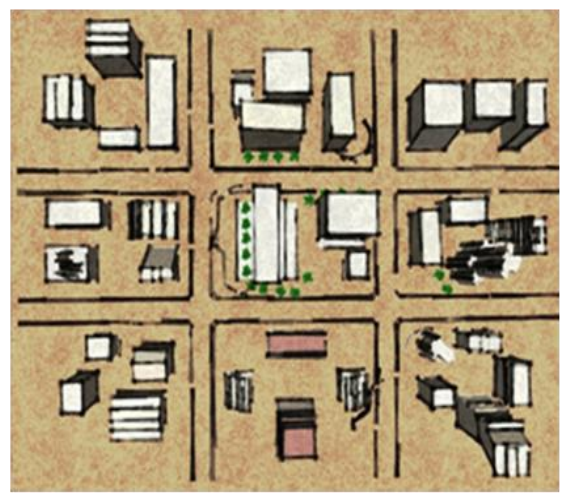

Figure 8: Layout with the Addition of Landscape Elements

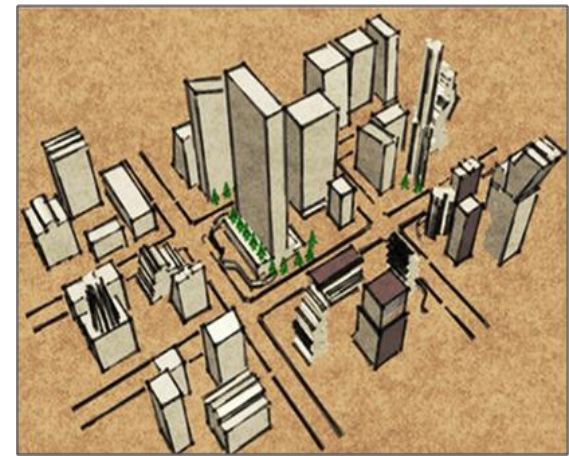

Figure 9: View of the Layout with the Addition of Landscape Elements

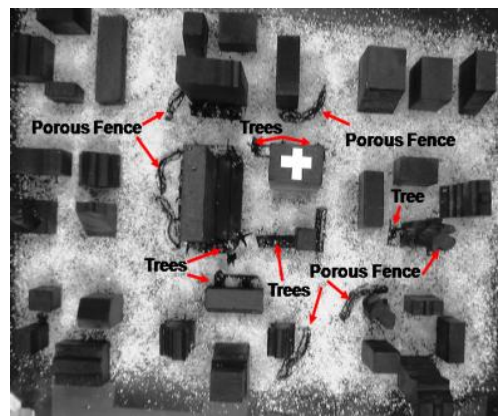

Figure 10: Bitmap Image Showing the Location of Landscape Elements with the Addition of Bran

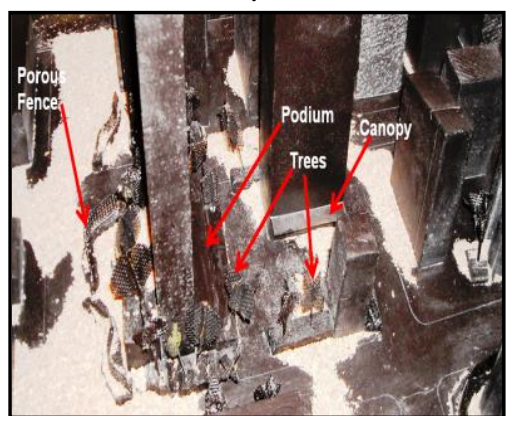

Figure 11: Erosion Patterns with Landscaping for $\mathrm{U}_{\mathrm{ref}}=5.75 \mathrm{~m} / \mathrm{s}$ for $\theta=0^{0}$

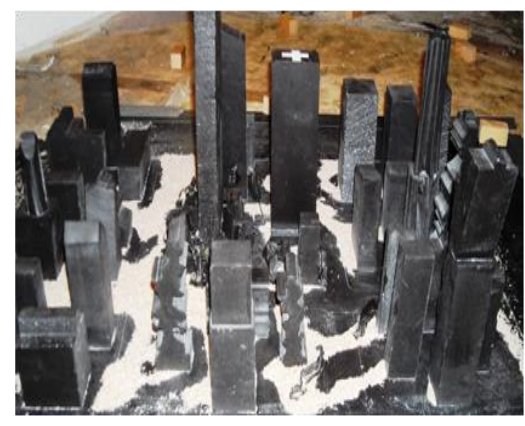

Figure12: Erosion Patterns Adjacent to Fences for

$$
\mathrm{U}_{\mathrm{ref}}=5.75 \mathrm{~m} / \mathrm{s} \text { for } \theta=0^{0}
$$




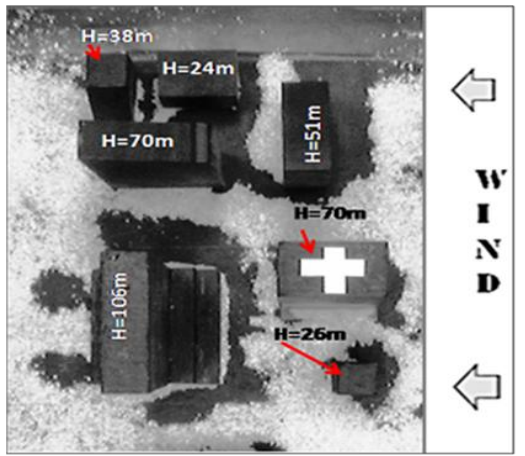

Figure 13(a): Erosion Patterns without Landscaping for $\mathrm{U}_{\text {ref }}=4.35 \mathrm{~m}$ for $\theta=0^{0}$

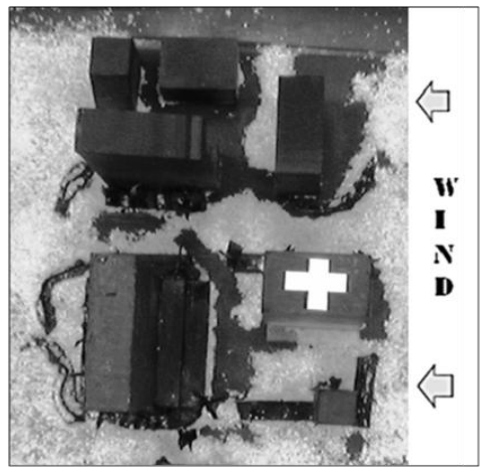

Figure 13(b): Erosion Patterns with Landscaping for $\mathrm{U}_{\text {ref }}=4.35 \mathrm{~m}$ for $\theta=0^{0}$

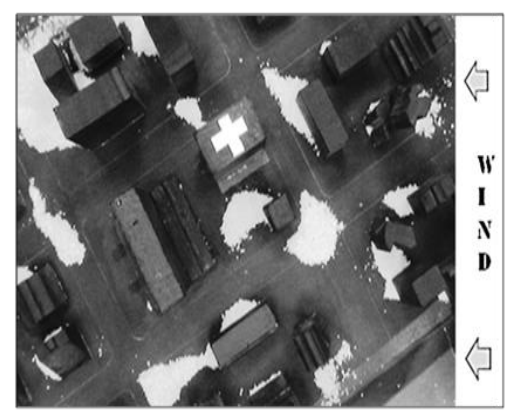

Figure 14(a): Erosion Patterns without Landscaping for $\mathrm{U}_{\mathrm{ref}}=5.75 \mathrm{~m} / \mathrm{s}$ for $\theta=30^{\circ}$

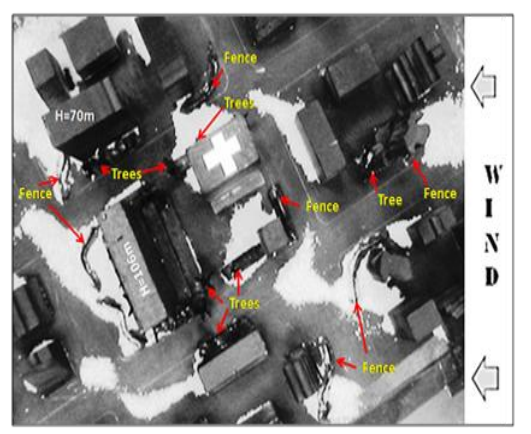

Figure 14(b): Erosion Patterns with Landscaping for $\mathrm{U}_{\text {ref }}=5.75 \mathrm{~m} / \mathrm{s}$ for $\theta=30^{\circ}$

\section{ANALYSIS AND PRESENTATION OF RESUlts}

Erosion patterns without landscaping for $\theta=0^{0}$ for $U_{\text {ref }}=$ $4.35 \mathrm{~m} / \mathrm{s}$ are shown in Figure 13(a). The erosion that occurs in the swirling eddies as seen by the erosion patterns formed in the rear of the tall building in Figure 13(a) are mitigated by the trees and fences in the rear of the tall building $106 \mathrm{~m}$ high as seen in the erosion patterns of Figure 13(b). Further erosion is reduced by the trees in the corners of the tall building also. The extent of the eroded areas is also reduced due to the fences adjacent to the $70 \mathrm{~m}$ building and the $51 \mathrm{~m}$ high building as seen in Figure 13(b). Bitmap images without and with landscaping for $\mathrm{U}_{\text {ref }}=5.75$ and $\theta=30^{\circ}$ are shown in Figures 14(a) and 14(b) respectively. Figure 14(b) brings out the effectiveness of porous fences in slowing down strong winds. Erosion patterns without and with landscaping for ten wind speeds for $\theta=30^{\circ}$ are shown in Figures 15(a) and 15(b) respectively. From these erosion patterns it is seen that the trees in the vicinity of the podium attached to the tall building $106 \mathrm{~m}$ high help in bringing down the discomfort factor from 1.42 to 0.64 .

Erosion patterns without and with landscaping for 10 wind speeds for $\theta=60^{\circ}$ are shown in Figures 16(a) and 16(b) respectively. The erosion patterns in Figure 16(a) show a discomfort factor of 1.75 in the corner and in front of the $70 \mathrm{~m}$ high tall building. Figure 16(b) shows a reduction in the discomfort factor from 1.75to 0.75 in front of the tall building $70 \mathrm{~m}$ high with the addition of trees. As seen from Figure 16(b). The fence adjacent to the $51 \mathrm{~m}$ high building also reduces the discomfort factor from 0.88 to less than 0.43 .

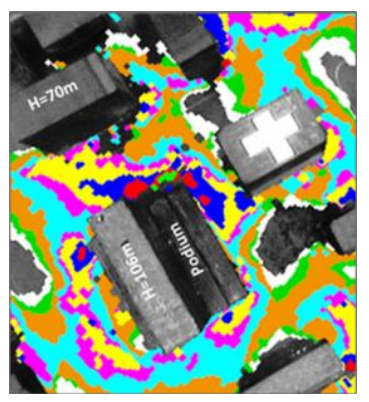

Figure 15(a): Erosion Patterns without Landscaping for Ten Wind Speeds for $\theta=30^{\circ}$

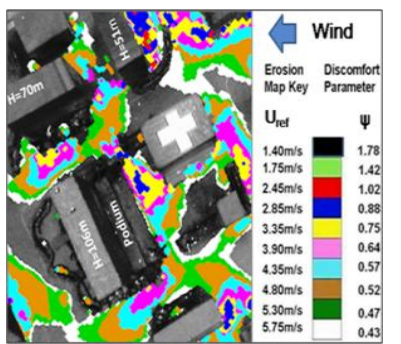

Figure 15(b): Erosion Patterns with Landscaping for Ten Wind Speeds for $\theta=30^{\circ}$ 


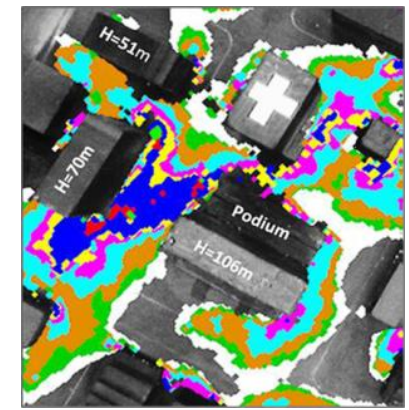

Figure 16(a): Erosion Patterns without Landscaping for Ten Wind Speeds for $\theta=60^{\circ}$

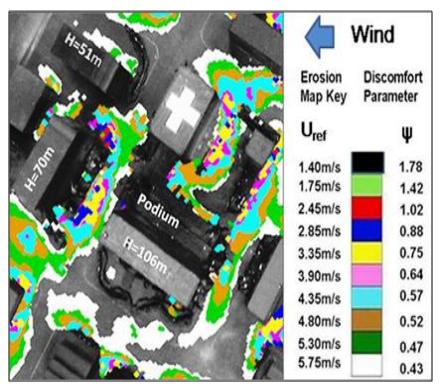

Figure 16(b): Erosion Patterns with Landscaping for Ten Wind Speeds for $\theta=60^{\circ}$

Erosion patterns without and with the addition of landscape elements for $U_{\text {ref }}=5.75 \mathrm{~m} / \mathrm{s}$ and $\theta=90^{\circ}$ is shown in Figures 17(a) and 17(b) respectively. The canopy in the front of the tall building with the + sign and the trees in the wake of this tall building help in reducing the wind speeds in the front and in the wake regions. The effect of the fences in diverting strong winds away from the front and corners of the buildings can also be seen from the uneroded areas adjacent to the fences.

Erosion patterns without and with landscaping for $\mathrm{U}$ ref $=4.35 \mathrm{~m} / \mathrm{s}$ and $\theta=210^{\circ}$ are shown in Figures $18(\mathrm{a})$ and $18(\mathrm{~b})$ respectively. The fences and trees on the windward face of the tall building help in reducing the impact of horizontal winds and the podium helps in dissipating the downward flow of vertical winds. The trees and fence adjacent to the $26 \mathrm{~m}$ high building help in reducing the erosion along the street abutting the cluster. The trees and fence adjacent to the $70 \mathrm{~m}$ high building to the right of the $51 \mathrm{~m}$ high building also help in mitigating the effect of the horizontal winds as seen in Figure 18(b).

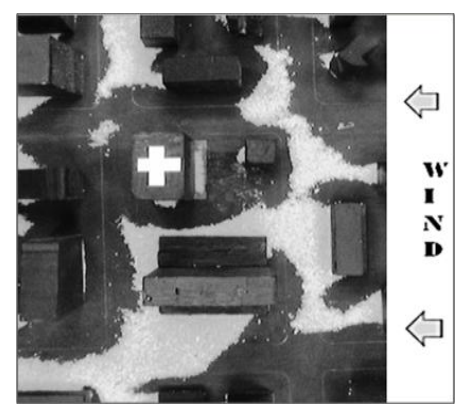

Figure17 (a): Erosion Patterns without Landscaping for $\mathrm{U}_{\text {ref }}=5.75 \mathrm{~m} / \mathrm{s}$ and $\theta=90^{\circ}$

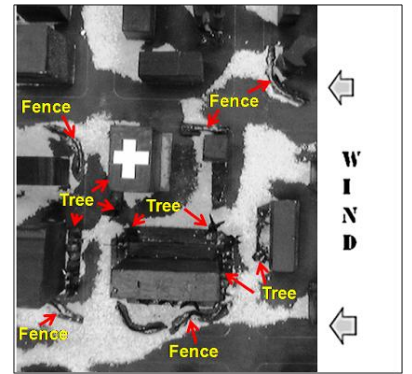

Figure 17(b): Erosion Patterns with Landscaping for $\mathrm{U}_{\text {ref }}=5.75 \mathrm{~m} / \mathrm{s}$ and $\theta=90^{\circ}$

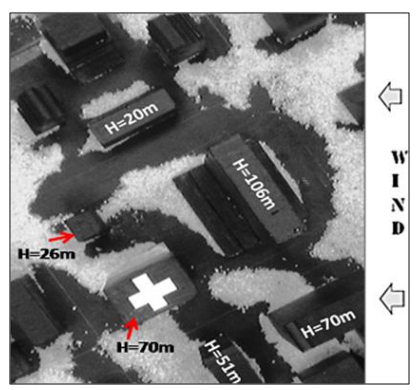

Figure18 (a): Erosion Patterns without Landscaping for $\mathrm{U}_{\mathrm{ref}}=4.35 \mathrm{~m} / \mathrm{s}$ for $\theta=210^{0}$

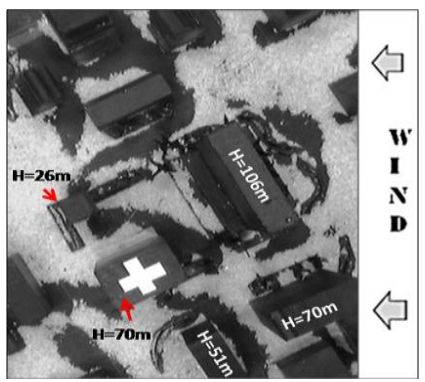

Figure 18 (b): Erosion Patterns with Landscaping for $\mathrm{U}_{\text {ref }}=4.35 \mathrm{~m} / \mathrm{s}$ for $\theta=210^{\circ}$

Erosion patterns without and with landscaping for $4.80 \mathrm{~m} / \mathrm{s}$ for $\theta=240^{\circ}$ are shown in Figures 19(a) and 19(b) respectively. A comparison of the erosion patterns in these two figures clearly brings out the effectiveness of the trees and fences adjacent to the tall building $106 \mathrm{~m}$ high. Erosion patterns without and with landscaping for ten wind speeds for $\theta=240^{\circ}$ are shown in Figures 20(a) and Figure 20b respectively. A comparison of these two figures shows a reduction of erosion in the central cluster with the $106 \mathrm{~m}$ high building due to the addition of trees. Although a reduction in wind speeds is noticed in the wake of the tall building in the central cluster, increase in discomfort factor in front of the $41 \mathrm{~m}$ building (Figure 20b) indicates that the fences more or less divert strong winds from one area to another. 


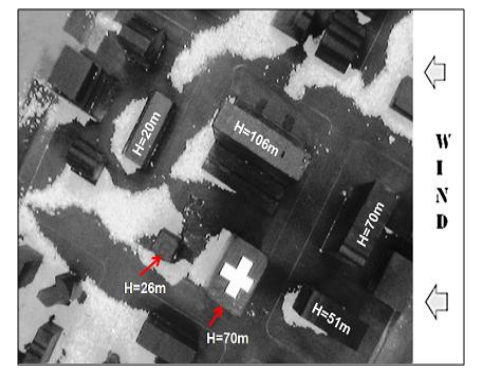

Figure 19 (a): Erosion Patterns without Landscaping for $\mathrm{U}_{\text {ref }}=4.80 \mathrm{~m} / \mathrm{s}$ for $\theta=240^{\circ}$

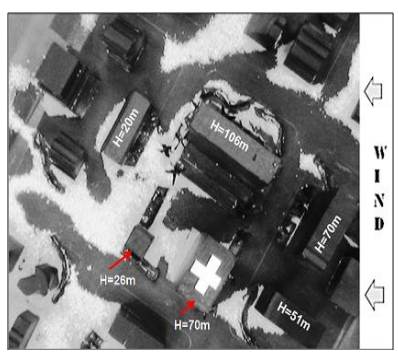

Figure 19(b): Erosion patterns with landscaping for $\mathrm{U}_{\text {ref }}=4.80 \mathrm{~m} / \mathrm{s}$ for $\theta=240^{\circ}$

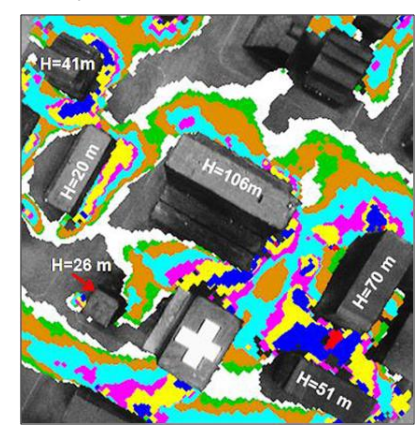

Figure 20(a): Erosion Patterns without Landscaping for Ten Wind Speeds for $\theta=240^{\circ}$

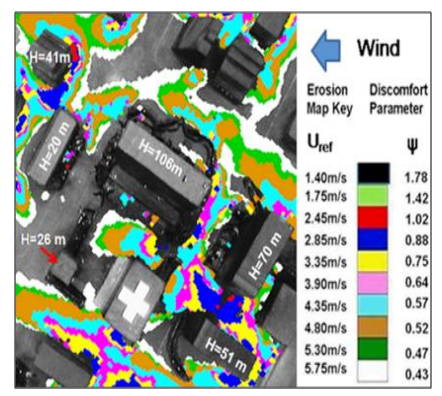

Figure 20 (b): Erosion Patterns with Landscaping for Ten Wind Speeds for $\theta=240^{\circ}$

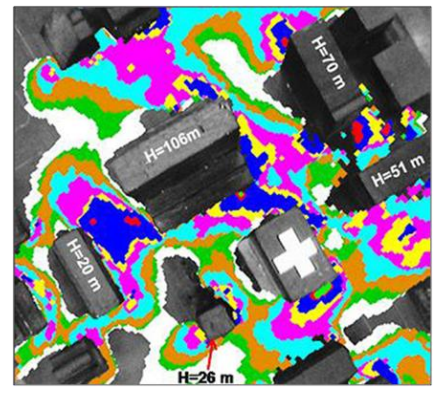

Figure 21(a): Erosion Patterns with Landscaping for Ten Wind Speeds for $\theta=300^{\circ}$

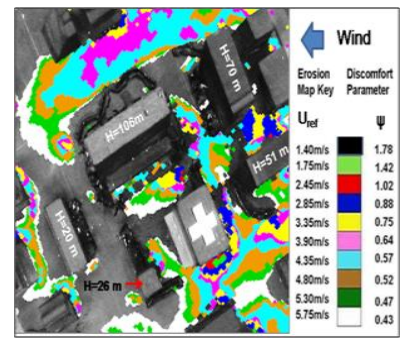

Figure 21(b): Erosion patterns with Landscaping for Ten wind Speeds for $\theta=300^{\circ}$

Erosion patterns without and with landscaping for ten wind speeds for $\theta=300^{\circ}$ are shown in Figures 21(a) and 21(b) respectively. The discomfort factor ranging from 1.02 to 0.88 in the space between the tall building $106 \mathrm{~m}$ high and $20 \mathrm{~m}$ high building is brought down to less than $0.43 \mathrm{~m} / \mathrm{s}$. The fence adjacent to the $26 \mathrm{~m}$ high building (Figure 21b) also helps in reducing the erosion in the central cluster.

\subsection{Comfort Category Maps}

According to the Auckland City Council wind comfort criteria, pedestrian activities in areas such as parks, outdoor cafes and plazas where people sit for long periods fall under Category A and the mean wind speed in such areas should be less than $4.3 \mathrm{~m} / \mathrm{s}$ for $99 \%$ of the time. Areas where pedestrians sit for short periods fall under Category B and in such areas the mean wind speed should be less than $6.4 \mathrm{~m} / \mathrm{s}$ for $99 \%$ of the time. For Category $\mathrm{C}$ areas, which include general footpaths and areas around buildings, the threshold mean speed is $8.3 \mathrm{~m} / \mathrm{s}$ which should not be exceeded for $1 \%$ of the time, or in other words the mean speed in such areas should be less than $8.3 \mathrm{~m} / \mathrm{s}$ for $99 \%$ of the time. Car parks and carriageways come under Category D areas where the mean speed should be less than $10.3 \mathrm{~m} / \mathrm{s}$ for $99 \%$ of the time. Areas where the wind speed exceeds $10.3 \mathrm{~m} / \mathrm{s}$ for more than $1 \%$ of the time are considered dangerous for pedestrians and permission is not accorded for category $\mathrm{E}$ areas in any proposed development [10].

Comfort category maps without landscaping and with landscaping are shown in Figures 22 (a) and 22(b) respectively. The comfort category map without landscaping shows excessive windy areas on the road between the tall building in the central cluster and the adjacent $70 \mathrm{~m}$ high building. The prevalence of category $\mathrm{D}$ areas is also seen at the edge of the $70 \mathrm{~m}$ high building which indicates that these areas would be excessively windy for pedestrian movement. 
A comparison of Figures 22(a) and 22(b) shows that the blue patch, which indicates a category $\mathrm{D}$ area (where wind speeds are permitted to be more than $10 \mathrm{~m} / \mathrm{s} 99 \%$ of the time), is totally eliminated with the addition of mitigation features in the form of plantings and converted into a category B area which is suitable for short periods of sitting. The conversion of red patches to green indicates that areas that were earlier suitable only for walking with permitted wind speeds in excess of $8 \mathrm{~m} / \mathrm{s}$ for 99 percent of the time are converted to category B areas which are suitable for sitting for short periods of time.

Further the conversion of the green patches to white (with the help of the porous fences) in the rear of the tall building and elsewhere indicates that these areas could now be used for sitting, eating and reading i.e. one could sit and read a newspaper in these areas without it being blown away.

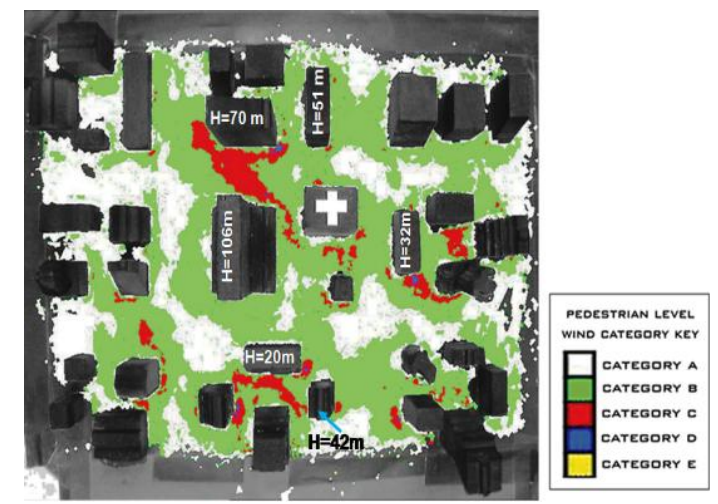

Figure 22(a): Comfort Category Maps Without Landscaping

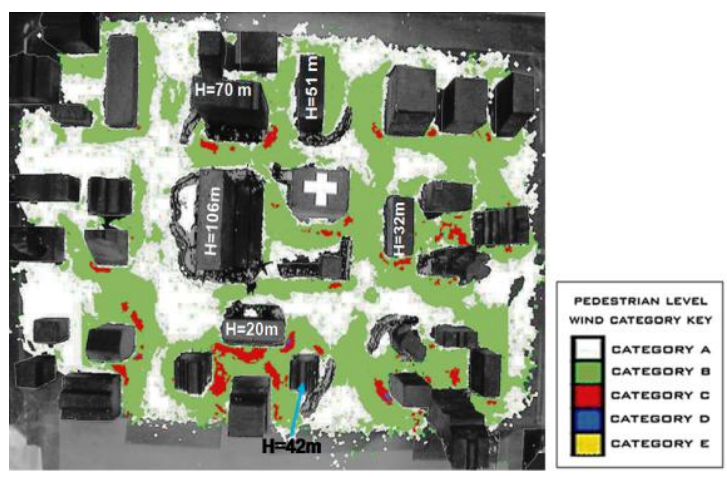

Figure 22 (b): Comfort Category Maps with Landscaping

Further the conversion of the green patches to white ( with the help of the porous fences) in the rear of the tall building and elsewhere indicates that these areas could now be used for sitting, eating and reading i.e. one could sit and read a newspaper in these areas without it being blown away.

\section{CONCLUSION AND FUtURE ENHANCEMENT}

This study has brought out the effectiveness of soft and hard landscape elements for mitigating adverse pedestrian level winds in the vicinity of tall buildings. Significant reduction in the discomfort parameter is seen in the corners, near wake and in the cluster spaces of tall buildings with the addition of trees and fences for all the wind directions tested for.
Trees planted in the corners of tall buildings can be effectively used for dissipating horizontal winds and also for guiding pedestrian movement away from windy zones. Substantial reduction in the comfort parameter $\psi$ from 1.02 to less than 0.43 can be achieved with the placement of trees and fences in the wake of the tall buildings.

Porous fences can be used with advantage for diverting strong winds away from areas of significant pedestrian use such as building entrances and passages between buildings. Further porous fences are preferable to solid barriers as increased turbulence is created in the wake of solid barriers.

Further research needs to be carried out to study the combined effect of architectural elements such as canopies, shading devices and landscape elements in moderating pedestrian winds. Selection of trees which also reduce air pollution and improve the air quality in the vicinity of buildings is another promising area of research.

\section{ACKNOWLEDGEMENT}

The authors wish to express their sincere thanks to the University of Auckland, New Zealand, Council of Architecture, New Delhi, India, Piloo Mody College of Architecture, Cuttack, India and the Centre of Excellence in Disaster Mitigation and Management, Indian Institute of Technology, Roorkee, India for providing financial grants for carrying out this study.

\section{REFERENCES}

[1] A.D. Penwarden, “Acceptable Wind Speed in Towns", Building Science, Vol.8, Pp.259-267, 1973.

[2] B. Blocken and J. Carmeliet, "Pedestrian Wind Environment around Buildings: Literature Review and Practical Examples", Journal of Thermal Envelope and Building Science, Vol.28, Pp.107-159, 2004.

[3] F. Livesey, D.Inculet, N. Isyumov, and A.G. Davenport, "A Scour Technique for the Evaluation of Pedestrian Winds", Journal of Wind Engineering and Industrial Aerodynamics, Vol. 36, Pp. 779-789, 1990.

[4] G.M. Heisler, "Mean wind speed below building height in residential neighborhoods with different tree density," ASHRAE Transactions, Vol. 96, Pp. 1389-2006, 1990.

[5] H. Akbari, M. Pomerantz, H. Taha, "Cool surface and shade trees to reduce energy and improve air quality in urban areas", Solar Energy, Vol. 70, Pp. 259-310, 2001

[6] K. Klem, "The influence of windscreen on wind flow" Proceedings: CSEB 07 PRAGUE, International Conference Central Europe towards Sustainable Building, 24-26 September,2007, Pp. 451-456, 2007.

[7] K. Mohan, "Study of Pedestrian Level Wind Environment in the Vicinity of Tall Buildings" PhD Thesis, Centre of Excellence in Disaster Mitigation and Management, Indian Institute of Technology, Roorkee, Roorkee, 2011.

[8] M. Eaddy and R.G.J. Flay, "Image Processing applied to pedestrian level wind investigations", IPENZ Transactions, Vol.25, No.1/EMCH, 1998.

[9] M. Eaddy ( 1990), " Pedestrian level wind measurement using computer image processing", ME Thesis, Mechanical Engineering Department, The University of Auckland, 1990.

[10] R.G.J. Flay, "Wind Environment Measurements and Acceptance Criteria developed at the University of Auckland", In: Proceedings of the Tenth Australasian Fluid Mechanics Conference, University of Melbourne, Melbourne, Australia, 11-15 Dec. 1989.

[11] W.J. Beranek and Van Koten, "Visual Techniques for the Determination of Wind Environment", Journal of Industrial Aerodynamics, Vol. 4, Pp. 295-306, 1979 


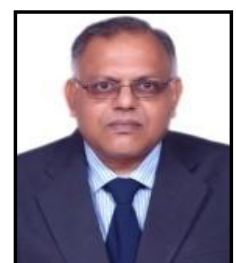

Prof.K. Mohan did his B.Arch. from Jawaharlal Nehru Technological University, Hyderabad in 1985 and M.Arch. from the Indian Institute of Technology, Kharagpur in 1988. He holds a P.G. Diploma in Environmental Studies from Andhra University and a P.G. Diploma in Environmental Economics from the Central University of Hyderabad. He obtained his Ph.D in Wind Engineering in 2012 from the Centre of Excellence in Disaster Mitigation and Management, Indian Institute of Technology, Roorkee, India. .He was the former Head of the Department of Architecture at KITS, Ramtek, Maharashtra and former Principal of PilooMody College of Architecture, Cuttack. Presently he is working as Senior Professor in the Gitam School of Architecture, Gitam University, Vishakhapatnam, and Andhra Pradesh. He is a Life Member of the Indian Institute of Architects, Indian Society for Technical Education and the Indian Institute of Wind Engineers. His research interests include Climate Responsive Design, Architectural Aerodynamics and Energy Efficient Landscape Design. (E-mail:profkmohan@gmail.com) 